\title{
Persulfate Wet Oxidation Method for the Determination of Total Phosphorus in Atmospheric Aerosols and Its Application for a Year-round Observation in Beijing
}

\author{
Tomoaki Okuda*, Yuma Gunji, Kebin $\mathrm{He}^{1)}$ and Yongliang Ma ${ }^{1)}$ \\ Department of Applied Chemistry, Faculty of Science and Technology, Keio University, 3-14-1 Hiyoshi, Kohoku-ku, \\ Yokohama 223-8522, Japan \\ ${ }^{1)}$ School of Environment, Tsinghua University, Beijing 100084, China \\ *Corresponding author. Tel: +81-45-566-1578, E-mail: okuda@applc.keio.ac.jp
}

\begin{abstract}
Measurement of the phosphorus concentration in aerosols in Beijing, which was a representative East Asian mega-city, was carried out. The optimum procedure for analyzing phosphorus in aerosols was found in this study. Recovery of phosphorus in environmental samples through the improved method was almost $100 \%$. The concentration of phosphorus in TSP was $145 \pm 47 \mathrm{ng} / \mathrm{m}^{3}$, with a seasonal variation showing high concentrations in winter and low concentrations in summer. The concentrations of phosphorus in $\mathrm{PM}_{2.5}$ accounted for $35 \pm 6 \%$ of those in TSP, with no seasonal variations. The major source of phosphorus in aerosols in Beijing was soil dust, and additional sources of phosphorus in fine particles could be coal combustion and biomass burning.
\end{abstract}

Key words: Phosphorous, TSP, $\mathrm{PM}_{2.5}$, Elements, East-Asia, Anthropogenic Emission, EDXRF, phosphoantimonylmolybdenum blue complex method

\section{INTRODUCTION}

Phosphorus is an essential nutrient for any organism living in terrestrial and ocean ecosystems (Paytan and McLaughlin, 2007). The deposition of essential nutrients from the air to the ocean surface plays an important role for primary production in phosphorus-limited oligotrophic open oceans (Furutani et al., 2010). Deposition of aerosols, which are originally derived from terrestrial regions, is an important process for phosphorus transport to these oligotrophic regions (Furutani et al., 2010; Mahowald et al., 2008). The concentration of phosphorus in urban areas can be high; in particular, phosphorus in aerosols in East Asia can be important, as it is transported to the oligotro- phic North Pacific region (Furutani et al., 2010; Chen and Chen, 2008; Mahowald et al., 2008; Chen et al., 2008, 2006). However, phosphorus concentration in aerosols in East Asian mega-cities has not been well characterized. In this study, concentrations of total phosphorus along with several kinds of elements in aerosols in Beijing, China, were measured.

There are several standardized methods for the determination of phosphorus in aqueous systems (JIS K0102, 2008; ISO 6878, 2004; Pai et al., 1990; Murphy and Riley, 1962). However, an analytical method for the determination of phosphorus in aerosols has not been well developed (Furutani et al., 2010). The persulfate wet oxidation method could be one possible solution to this problem. Another useful option for oxidative treatment is high-temperature dry combustion, which has been used for particulate phosphorus determination (Suzumura, 2008; Chen et al., 2006). In this study, an improved method for the determination of total phosphorus in aerosols was developed.

\section{EXPERIMENTAL}

\subsection{Development of an Improved Method for the Determination of Phosphorus in Aerosols}

In this study, modifications to the persulfate wet oxidation methods reported previously have been applied (JIS K0102, 2008; ISO 6878, 2004; Pai et al., 1990; Murphy and Riley, 1962). The procedure developed in this study, which is known as phosphoantimonylmolybdenum blue complex (PD-MB) method, is described below.

A filter segment was placed in a PTFE container, and then $8 \mathrm{~mL}$ of $40 \mathrm{~g} / \mathrm{L}$ potassium persulfate solution was added. The sample container was autoclaved for 
$30 \mathrm{~min}$ at $120^{\circ} \mathrm{C}$ and colorimetric determination of phosphate was subsequently performed. The solution was filtered by passing through a membrane filter (Advantec DISMIC, pore size: $0.2 \mu \mathrm{m}$ ). In order to develop the color of the solution for the colorimetric determination of phosphate, two solutions were prepared. Solution 1: $72 \mathrm{~g} / \mathrm{L} \mathrm{L}(+)$-ascorbic acid (99.6\%, Wako); solution 2: $12 \mathrm{~g}$ of ammonium heptamolybdate tetrahydrate $\left[\left(\mathrm{NH}_{4}\right)_{6} \mathrm{Mo}_{7} \mathrm{O}_{24} \cdot 4 \mathrm{H}_{2} \mathrm{O}\right](99 \%$, Wako), $0.48 \mathrm{~g}$ of bis $[(+)$-tartorato]diantimonate(III) dipotassium trihydrate $\left[\mathrm{K}_{2}(\mathrm{SbO})_{2} \mathrm{C}_{8} \mathrm{H}_{4} \mathrm{O}_{10} \cdot 3 \mathrm{H}_{2} \mathrm{O}\right](99.5 \%$, Wako), $240 \mathrm{~mL}$ of $78 \%$ sulfuric acid (95\%, Wako), and $10 \mathrm{~g}$ of ammonium amidosulfate $\left[\mathrm{NH}_{4} \mathrm{OSO}_{2} \mathrm{NH}_{2}\right]$ $(98.5 \%$, Wako) in $1 \mathrm{~L}$ of ultrapure water. Immediately before the experiment, the color-development solution was mixed at a ratio of $1: 5$ of solution 1 to solution 2. Color-development solution $(0.8 \mathrm{~mL})$ was added to the sample filtrate, and then settling was allowed to occur for a certain amount of time (the color development time). The colorimetric determination of phosphate of the final solution at $880 \mathrm{~nm}$ and $1 \mathrm{~cm}$ optical path length was carried out using a spectrophotometer (Shimadzu UV-mini1240). High linearity of the calibration curve $\left(r^{2}=0.9999\right)$ was obtained by analyzing ultrapure water and phosphate standard solutions $(0.1,0.2,0.5,1,2$ and $5 \mu \mathrm{g} / \mathrm{mL})$ using the spectrophotometer. The detection limit, which was calculated by tripling the standard deviation of replicate absorbance measurements $(n=5)$ of ultrapure water (blank solution), was $0.07 \mu \mathrm{g} / \mathrm{mL}$. The phosphate concentration in the final solution was adjusted to higher than $0.1 \mu \mathrm{g} / \mathrm{mL}$ (JIS K0102, 2008; ISO 6878, 2004).

In this study, optimization of the color development time was examined. The standard reference material for aerosol (NIES CRM\#28, Mori et al., 2008), which was collected at Beijing, China, was used in the experiment. Phosphorus recovery was determined using 1-5 $\mathrm{mg}$ of CRM\#28. Furthermore, several reference materials were also used for testing the phosphorus recovery by the procedure developed in this study.

\section{2 Aerosol Collection}

Total suspended particles (TSP) and $\mathrm{PM}_{2.5}$ (particulate matter less than $2.5 \mu \mathrm{m}$ ) were collected using cellulose nitrate membrane filters $(0.8 \mu \mathrm{m}$ of pore size, Millipore AAWP04700) on the rooftop of a building (5 $\mathrm{m}$ above the ground) at Tsinghua University. The site was located $15 \mathrm{~km}$ northwest of the center of Beijing city, China (Okuda et al., 2013a, b, 2011, 2008). This site could be considered a good representative of the entire area of Beijing city in terms of the concentrations of particulate matter (Okuda et al., 2004). A low volume air sampler (Tokyo Dylec Corp.) was operated at $5 \mathrm{~L} / \mathrm{min}$ for $1 \mathrm{week}$ to collect aerosol samples.
A multinozzle cascade impactor (NL-5-2.5A, Tokyo Dylec Corp.) was used to collect $\mathrm{PM}_{2.5}$ (Okuda and Hatoya, 2013; Okuda et al., 2007a, b). Sampling was conducted for 1 year $(n=41)$, from January to December 2008 .

\subsection{Energy-dispersive X-ray Fluorescence Spectrometry (EDXRF)}

All elements (except for phosphorus) on the filter samples without pretreatment were analyzed by EDXRF using an EDXL300 spectrometer (Rigaku Corp., Japan). Quantification of each element in aerosol samples was performed using the fundamental parameter (FP) method Rigaku Profile Fitting - Spectra Quant X (RPF-SQX). Thirteen elements (Al, S, K, Ca, $\mathrm{Ti}, \mathrm{V}, \mathrm{Cr}, \mathrm{Mn}, \mathrm{Fe}, \mathrm{Ni}, \mathrm{Cu}, \mathrm{Zn}$, and $\mathrm{Pb}$ ) were measured in this study. A detailed procedure for the multi-elemental analysis is described elsewhere (Okuda and Hatoya, 2013; Okuda et al., 2013a). Phosphorus concentrations could be measured by EDXRF; however, in this study they were undetectable through this method since the concentrations were almost always below the detection limit.

\section{RESULTS AND DISCUSSION}

\subsection{Optimization of the Color Development Time for the Phosphorus Determination}

The color development time for phosphorus determination using the persulfate wet oxidation-phosphoantimonylmolybdenum blue complex method (PDMB method) was set at $15 \mathrm{~min}$ (JIS K0102, 2008) or 10-30 min (ISO 6878, 2004). However, we found that the absorbance of the sample solution continued to increase even after $30 \mathrm{~min}$ had passed since the beginning of color development. This increase was possibly due to the considerably lowered rate of reduction of the antimony phosphomolybdate complex caused by ascorbic acid at high concentration of protons provided by potassium persulfate (Pai et al., 1990). Thus, the color development time for the PD-MB method was optimized.

The standard reference material for aerosol (NIES CRM\#28), which had a reference value of total phosphorus $(0.145 \mathrm{wt} \%)$, was subjected to the PD-MB method. The absorbance of the sample solution corresponding to elapsed time since the color-development solutions were added to the sample solution was recorded. Ambient temperature ranged from 20 to $28^{\circ} \mathrm{C}$ during the experiments $(n=5)$. Recovery of total phosphorus was calculated on the basis of the absorbance (Fig. 1). The recovery of phosphorus was significantly lower than $100 \%$ when the color development time 


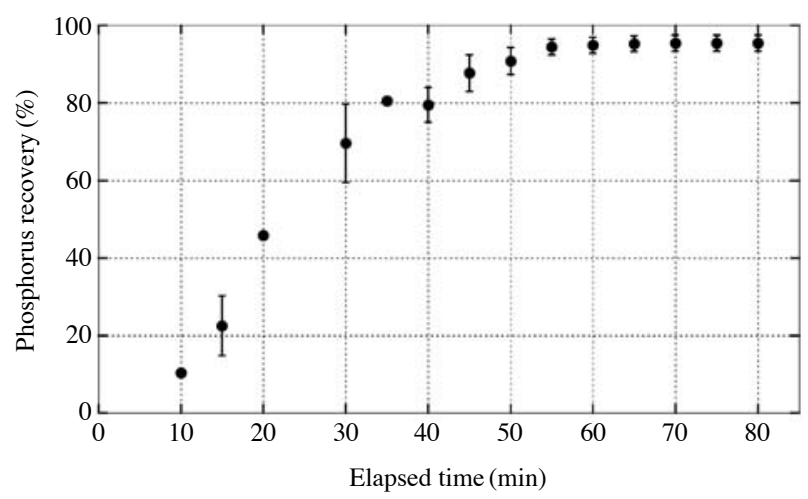

Fig. 1. Phosphorus recovery for NIES CRM\#28 corresponding to time elapsed since the addition of color-development solutions to the sample solution.

was 15 or $30 \mathrm{~min}$. The recovery was stable at approximately $95 \%$ after $60 \mathrm{~min}$. Therefore, it was decided that the color development time was $60 \mathrm{~min}$ in this study. The recovery of phosphorus in CRM\#28 using the fixed method was $95 \pm 3 \%(n=5)$. Note that the PD-MB method may cause lower recovery for phosphorus in clay minerals (Suzumura, 2008). Despite this potential weakness, total phosphorus was successfully measured through the PD-MB method developed in this study since this method showed high recovery of phosphorus $(95 \pm 3 \%)$ for CRM\#28, which was urban aerosol material collected at Beijing. The high recovery of phosphorus remained consistent when the amount of CRM\#28 was increased from $1.22 \mathrm{mg}$ to $14.7 \mathrm{mg}$.

Higher concentrations of silicate may cause a positive artifact for phosphorus determination by the PDMB method (ISO 6878, 2004). However, a solution of silicate and phosphate (Si: $500 \mu \mathrm{g} / \mathrm{mL}, \mathrm{P}: 0.5 \mu \mathrm{g} / \mathrm{mL}$ ) showed almost identical absorbance to the solution with the same concentration of phosphorus $(0.5 \mu \mathrm{g} /$ $\mathrm{mL}$ ) but without silicate. Therefore, interference by silicate could be ignored when the PD-MB method was used in this study.

\section{2 Recovery of Phosphorus of Various Reference Materials}

Recovery of phosphorus from various reference materials was examined using the fixed PD-MB method. In this study, seven types of reference material (Geochemical Reference Samples, provided by National Institute of Advanced Industrial Science and Technology, Japan (AIST, 2013), JB-1b $\left(\mathrm{P}_{2} \mathrm{O}_{5}\right.$ content, $0.255 \%)$, JH-1 (0.099\%), JSd-1 (0.122\%), JA-2 (0.146\%), JB-3 (0.294\%), JG-1a (0.083\%), and JGb-1 $(0.056 \%))$ were analyzed using this method. All of the reference materials were igneous rocks except for

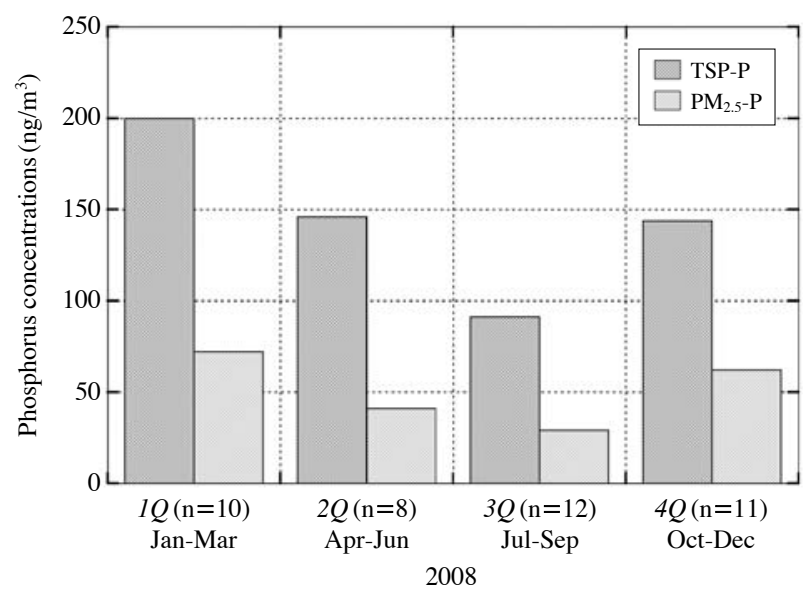

Fig. 2. Phosphorus concentrations in TSP and $\mathrm{PM}_{2.5}$ in Beijing in 2008.

JSd-1 (sedimentary rock). ATP (adenosine 5'-triphosphate disodium salt tryhydrate) was also examined as a surrogate for an organic form of phosphorus. The results showed that the recovery of phosphorus from geochemical reference samples was $102 \pm 8 \%(n=7)$, and that of ATP was $96 \pm 2 \%(n=4)$. Therefore, the PD-MB method could be applied to determine the total phosphorus content in various environmental samples.

\section{3 Measurement of the Concentrations of Phosphorus in Aerosols in Beijing, China}

According to previous studies, the concentration of phosphorus in aerosols could be too low to obtain analytical results by the PD-MB method using a single filter sample (Furutani et al., 2010; Luo et al., 2010; Chen et al., 2006). Hence, several samples were analyzed together in order to obtain a sufficient amount of phosphorus for detection using the PD-MB method. We divided 41 samples into 4 periods, namely, 1Q: January to March $(n=10), 2 Q$ : April to June $(n=8)$, 3Q: July to September $(n=12)$, and 4Q: October to December $(n=11)$. The results are shown in Fig. 2. The concentration of phosphorus in TSP was $145 \pm$ $47 \mathrm{ng} / \mathrm{m}^{3}$, with a seasonal variation showing high concentrations in winter and low concentrations in summer. A similar trend was observed at Lake Taihu, near Shanghai, located approximately $1,000 \mathrm{~km}$ south of Beijing (Luo et al., 2010). The concentration of phosphorus in Beijing was one order of magnitude higher than that on the North Pacific Ocean (Furutani et al., 2010), and it was several times higher than that in Taiwan (Chen et al., 2008). The concentrations of phosphorus in $\mathrm{PM}_{2.5}$ accounted for $35 \pm 6 \%$ of those in 
TSP, with no seasonal variations. These results are at a level similar to those found in a previous report for East Asian aerosols (Beijing, Hong Kong, Cheju, and Sado Island, Zhang et al., 2010; Cohen et al., 2004) and that for the North Pacific (Furutani et al., 2010). It was found that less than $50 \%$ of phosphorus in Beijing existed in $\mathrm{PM}_{2.5}$.

\subsection{Possible Sources of Phosphorus in Aerosols in Beijing, China}

Possible sources of phosphorus in Beijing aerosols for coarse particles (TSP-PM ${ }_{2.5}$ ) and fine particles $\left(\mathrm{PM}_{2.5}\right)$ are discussed separately. The enrichment factors (EFs) for each element in both fine and coarse modes were calculated. In this study, the EF of phosphorus is defined as $\mathrm{EF}=(\mathrm{P} / \mathrm{Fe})_{\text {aerosol }} /(\mathrm{P} / \mathrm{Fe})_{\text {crust }}$, where $(\mathrm{P} / \mathrm{Fe})_{\text {aerosol }}$ is the concentration ratio of phosphorus to $\mathrm{Fe}$ (the reference element) in the aerosol, and $(\mathrm{P} / \mathrm{Fe})_{\text {crust }}$ is the concentration ratio of $\mathrm{P}$ to $\mathrm{Fe}$ in continental crust (Mason and Moore, 1982). Given that crustal sources are the primary source of $\mathrm{Fe}$ and $\mathrm{Fe}$ is stable (not altered) in the atmosphere, this element was chosen as the reference element. The results of the EF calculation are shown in Fig. 3. Element concentrations measured in this study are shown in Tables 1 and 2. The EFs of elements in TSP observed in this study were similar to those reported in a previous study (Okuda et al., 2013b).

The EF of phosphorus in coarse particles is $1.5 \pm$ 0.3 , which is similar to the $\mathrm{EFs}$ of $\mathrm{Al}, \mathrm{Ca}$, and Ti, ele- ments that are generally considered to be of crustal origin. Therefore, it is reasonable that phosphorus in coarse particles originated from soil dust. This can also explain the seasonal variation in phosphorus concentration, which was high in winter and low in summer, since soil dust transport would be more active in winter because of the Asian monsoon. On the other hand, the EF of phosphorus in fine particles was 4.3 \pm 1.4 , which was higher than that in coarse particles. This value is also different from the EFs of crustal

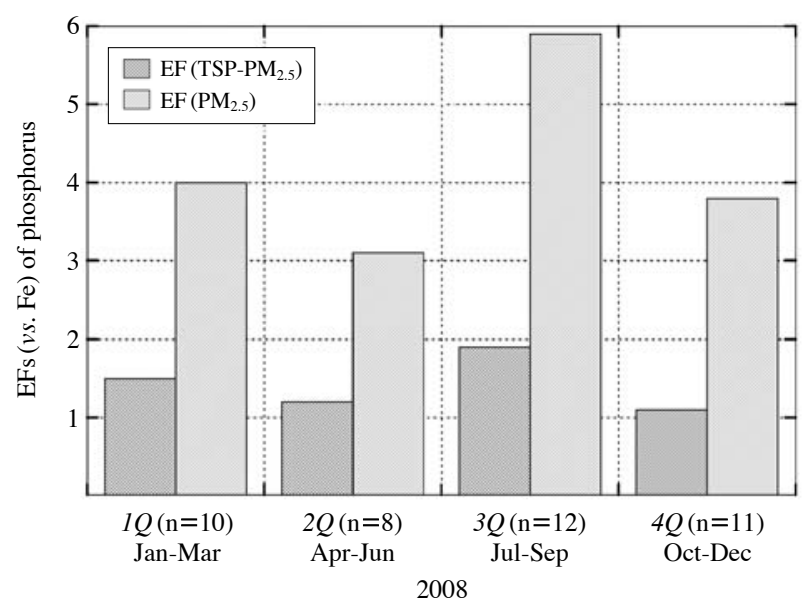

Fig. 3. Enrichment factors ( $v s$. Fe) for phosphorus in aerosols in coarse $\left(\mathrm{TSP}-\mathrm{PM}_{2.5}\right)$ and fine $\left(\mathrm{PM}_{2.5}\right)$ mode in Beijing in 2008.

Table 1. The concentrations of elements in aerosols in Beijing, China in 2008.

\begin{tabular}{|c|c|c|c|c|c|c|c|c|c|c|c|c|c|}
\hline Elements $^{\mathrm{a}}$ & $\begin{array}{l}\text { Conc. in } \\
\text { TSP } \\
{\left[\mathrm{ng} / \mathrm{m}^{3}\right]}\end{array}$ & SD & $\begin{array}{c}\mathrm{EF}^{\mathrm{b}} \\
(v s . \mathrm{Fe})\end{array}$ & $\begin{array}{l}\text { Conc. in } \\
\text { coarse }^{c} \\
\text { particles } \\
{\left[\mathrm{ng} / \mathrm{m}^{3}\right]}\end{array}$ & SD & $\begin{array}{c}\mathrm{EF} \\
(v s . \mathrm{Fe})\end{array}$ & SD & $\begin{array}{c}\text { Conc. in } \\
\text { fine }^{\mathrm{d}} \text { particles } \\
{\left[\mathrm{ng} / \mathrm{m}^{3}\right]}\end{array}$ & SD & $\begin{array}{c}\mathrm{EF} \\
(v s . \mathrm{Fe})\end{array}$ & SD & $\begin{array}{l}\text { Fine/ } \\
\text { Coarse }\end{array}$ & SD \\
\hline $\mathrm{Al}$ & 3301 & 1275 & 0.5 & 2768 & 1067 & 0.5 & 0.1 & 533 & 266 & 0.5 & 0.1 & 0.2 & 0.1 \\
\hline $\mathrm{P}$ & 145 & 47 & 1.8 & 94 & 29 & 1.5 & 0.3 & 51 & 20 & 4.3 & 1.4 & 0.5 & 0.1 \\
\hline S & 5815 & 1384 & 287 & 1673 & 1110 & 107 & 61 & 4142 & 709 & 1754 & 1334 & 4.3 & 4.1 \\
\hline $\mathrm{K}$ & 2347 & 1010 & 1.2 & 1096 & 459 & 0.6 & 0.1 & 1251 & 653 & 3.9 & 0.6 & 1.1 & 0.4 \\
\hline $\mathrm{Ca}$ & 7476 & 3389 & 2.6 & 6471 & 2974 & 2.7 & 0.5 & 1005 & 482 & 2.2 & 0.3 & 0.2 & 0.0 \\
\hline $\mathrm{Ti}$ & 360 & 148 & 1.1 & 293 & 118 & 1.0 & 0.1 & 68 & 31 & 1.3 & 0.1 & 0.2 & 0.0 \\
\hline $\mathrm{V}$ & 14.7 & 5.8 & 1.4 & 10.2 & 6.0 & 1.0 & 0.5 & 4.5 & 0.5 & 2.3 & 0.4 & 0.5 & 0.3 \\
\hline $\mathrm{Cr}$ & 12.5 & 3.2 & 1.6 & 7.7 & 2.4 & 1.2 & 0.1 & 4.9 & 1.5 & 5.2 & 3.9 & 0.7 & 0.3 \\
\hline $\mathrm{Mn}$ & 125 & 48 & 1.7 & 71 & 29 & 1.1 & 0.1 & 54 & 21 & 5.0 & 1.4 & 0.8 & 0.2 \\
\hline $\mathrm{Fe}$ & 3890 & 1504 & 1.0 & 3277 & 1224 & 1.0 & 0.0 & 613 & 283 & 1.0 & 0.0 & 0.2 & 0.0 \\
\hline $\mathrm{Ni}$ & 13.6 & 3.7 & 2.3 & 6.9 & 3.6 & 1.3 & 0.3 & 6.6 & 2.9 & 11.0 & 12.1 & 1.6 & 1.9 \\
\hline $\mathrm{Cu}$ & 56 & 16 & 13.1 & 21 & 7 & 6.2 & 1.7 & 35 & 12 & 57.7 & 17.6 & 1.7 & 0.6 \\
\hline $\mathrm{Zn}$ & 387 & 156 & 71.1 & 126 & 65 & 27.9 & 10.3 & 262 & 105 & 317 & 43 & 2.3 & 1.0 \\
\hline $\mathrm{Pb}$ & 179 & 60 & 177 & 30 & 18 & 37.7 & 17.8 & 149 & 53 & 1000 & 195 & 6.7 & 5.9 \\
\hline
\end{tabular}

${ }^{a}$ All elements were determined by EDXRF except for P, which was determined by the phosphoantimonylmolybdenum blue complex method. SD means the standard deviation for each season $(n=4)$.

${ }^{b}$ Elemental composition of continental crust was cited from Mason and Moore, 1982.

${ }^{\mathrm{c}}$ Coarse particles mean [TSP]-[ $\left.\mathrm{PM}_{2.5}\right]$.

${ }^{\mathrm{d}}$ Fine particles mean $\left[\mathrm{PM}_{2.5}\right]$. 


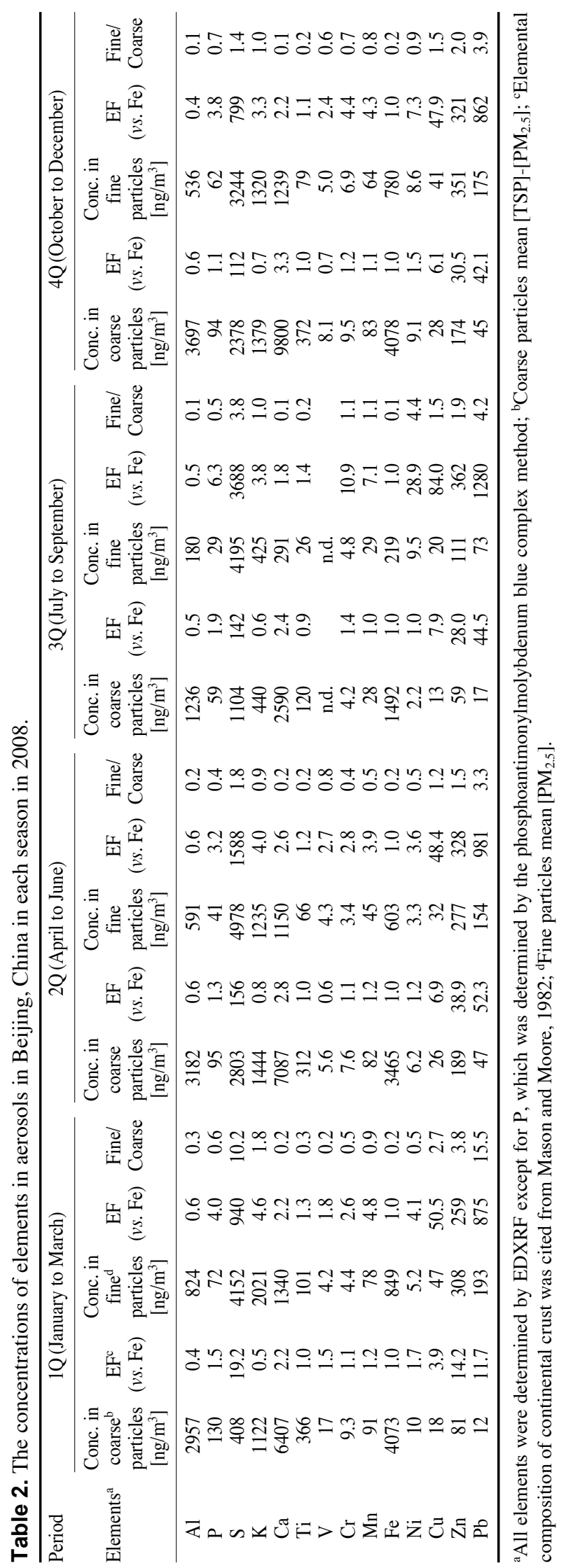

elements in fine particles. This EF value suggests that the phosphorus in fine particles were mainly soil dust, but additional sources should also be considered. The correlation coefficients between concentrations of phosphorus and other elements for each season were calculated. In fine particles, the highest correlation was observed between phosphorus and copper $\left(\mathrm{r}^{2}=\right.$ 0.97). The correlations between phosphorus and zinc $\left(r^{2}=0.69\right)$, and phosphorus and lead $\left(r^{2}=0.83\right)$ in fine particles are also high. On the contrary, the correlations among these elements in coarse particles were low (P-Cu: $\mathrm{r}^{2}=0.07 ; \mathrm{P}-\mathrm{Zn}: \mathrm{r}^{2}=0.02 ; \mathrm{P}-\mathrm{Pb}: \mathrm{r}^{2}=0.01$ ). A possible source of copper, zinc, and lead could be coal combustion (Okuda et al., 2008). A previous study suggested that coal combustion would be a significant source of phosphorus in aerosols near Shanghai (Luo et al., 2010). Therefore, one of the possible sources of phosphorus in fine particles in Beijing could be coal combustion. Another possible source of phosphorus is biomass burning, since the correlation between phosphorus and potassium, which is often considered a tracer for biomass burning, is high $\left(\mathrm{r}^{2}=0.85\right)$. Gas phase phosphorus such as $\mathrm{PH}_{3}$ may also contribute to the aerosol-phase phosphorus through its uptake, nucleation and oxidation (Furutani et al., 2010; Zhu et al., 2007).

The coastal or open ocean ecosystem can be greatly affected by the atmospheric phosphorus transported from the terrestrial region (Furutani et al., 2010; Mahowald et al., 2008). However, the urban environment itself does not seem to play a significant role to add extra amount of phosphorus, since the major source of phosphorus in aerosols is still soil dust even in an urban environment, such as Beijing city.

\section{CONCLUSIONS}

Measurement of the phosphorus concentration in aerosols in Beijing, which was a representative East Asian mega-city, was carried out. The optimum procedure for analyzing phosphorus in aerosols was found in this study. Recovery of phosphorus in environmental samples through the improved method was almost $100 \%$. The concentration of phosphorus in TSP was $145 \pm 47 \mathrm{ng} / \mathrm{m}^{3}$, with a seasonal variation showing high concentrations in winter and low concentrations in summer. The concentrations of phosphorus in $\mathrm{PM}_{2.5}$ accounted for $35 \pm 6 \%$ of those in TSP, with no seasonal variations. The major source of phosphorus in aerosols in Beijing was soil dust, and additional sources of phosphorus in fine particles could be coal combustion and biomass burning. 


\section{ACKNOWLEDGEMENT}

This research was supported partly by funds from the Grant-in-Aid for Scientific Research (22710016 and 23120707) of Ministry of Education, Culture, Sports, Science and Technology (MEXT), Japan, the Environment Research and Technology Development Fund (B-0904) of Ministry of the Environment, Japan, Steel Industry Foundation for the Advancement of Environmental Protection Technology, and Mizuho Foundation for the Promotion of Sciences. We would like to thank Prof. S. Tanaka for his support.

\section{REFERENCES}

AIST (National Institute of Advanced Industrial Science and Technology, Japan) (2013) GSJ Geochemical Reference samples DataBase. https://gbank.gsj.jp/ geostandards/welcome.html, accessed on August 31, 2013.

Chen, H.-Y., Chen, L.-D. (2008) Importance of anthropogenic inputs and continental-derived dust for the distribution and flux of water-soluble nitrogen and phosphorus species in aerosol within the atmosphere over the East China Sea. Journal of Geophysical Research 113, D11303, doi:10.1029/2007JD009491.

Chen, H.-Y., Fang, T.-H., Preston, M.R., Lin, S. (2006) Characterization of phosphorus in the aerosol of a coastal atmosphere: Using a sequential extraction method. Atmospheric Environment 40, 279-289.

Chen, H.-Y., Hung, C.-C., Fang, T.-H., Gong, G.-C. (2008) Dry deposition and particle-size distribution of phosphorus in the marine atmosphere over the northeastern coast of Taiwan. Continental Shelf Research 28, 756766.

Cohen, D.D., Garton, D., Stelcer, E., Hawas, O., Wang T., Poon, S., Kim, J., Choi, B.C., Oh, S.N., Shin, H.-J., Ko, M.Y., Uematsu, M. (2004) Multielemental analysis and characterization of fine aerosols at several key ACE-Asia sites. Journal of Geophysical Research 109, D19S12, doi:10.1029/2003JD003569.

Furutani, H., Meguro, A., Iguchi, H., Uematsu, M. (2010) Geographical distribution and sources of phosphorus in atmospheric aerosol over the North Pacific Ocean. Geophysical Research Letters 37, L03805, doi:10.1029/ 2009GL041367.

ISO 6878 (2004) Water quality - Determination of phosphorus - Ammonium molybdate spectrometric method.

JIS K0102 (2008) Testing method for industrial wastewater.

Luo, J., Wang, X., Yang, H., Yu, J.Z., Yang, L., Qing, B. (2010) Atmospheric phosphorus in the northern part of Lake Taihu, China. Chemosphere 84, 785-791.

Mason, B., Moore, C.B. (1982). Principles of Geochemistry, 4th ed., Wiley, New York.
Mahowald, N., Jickells, T.D., Baker, A.R., Artaxo, P., Benitez-Nelson, C.R., Bergametti, G., Bond, T.C., Chen, Y., Cohen, D.D., Herut, B., Kubilay, N., Losno, R., Luo, C., Maenhaut, W., McGee, K.A., Okin, G.S., Siefert, R.L., Tsukuda, S. (2008) Global distribution of atmospheric phosphorus sources, concentrations and deposition rates, and anthropogenic impacts. Global Biogeochemical Cycles 22, GB4026, doi:10.1029/ 2008 GB003240.

Mori, I., Sun, Z., Ukachi, M., Nagano, K., McLeod, C.W., Cox, A.G., Nishikawa, M. (2008) Development and certification of the new NIES CRM 28: urban aerosols for the determination of multielements. Analytical and Bioanalytical Chemistry 391, 1997-2003.

Murphy, J., Riley, J.P. (1962) A modified single solution method for the determination of phosphate in natural waters. Analytica Chimica Acta 27, 31-36.

Okuda, T., Fujimori, E., Hatoya, K., Takada, H., Kumata, H., Nakajima, F., Hatakeyama, S., Uchida, M., Tanaka, S., He, K., Ma, Y., Haraguchi, H. (2013a) Rapid and simple determination of multi-elements in aerosol samples collected on quartz fiber filters by using EDXRF coupled with fundamental parameter quantification technique. Aerosol and Air Quality Research, in press.

Okuda, T., Hatoya, K. (2013) Development of non-destructive simultaneous analytical method for multi-elements in $\mathrm{PM}_{2.5}$ using energy dispersive X-ray fluorescence spectrometry with a fundamental parameter quantification technique, Earozoru Kenkyu, in press (in Japanese with English abstract).

Okuda, T., Kato, J., Mori, J., Tenmoku, M., Suda, Y., Tanaka, S., He, K., Ma, Y., Yang, F., Yu, X., Duan, F., Lei, Y. (2004) Daily concentrations of trace metals in aerosols in Beijing, China, determined by using inductively coupled plasma mass spectrometry equipped with laser ablation analysis, and source identification of aerosols. Science of the Total Environment 330, 145158.

Okuda, T., Katsuno, M., Naoi, D., Nakao, S., Tanaka, S., He, K., Ma, Y., Lei, Y., Jia, Y. (2008). Trends in hazardous trace metal concentrations in aerosols collected in Beijing, China from 2001 to 2006. Chemosphere, 72, 917-924.

Okuda, T., Katsuno, M., Tanaka, S., Kondo, Y., Takegawa, N., Komazaki, Y.(2007a). Measurement and source identification of trace metals in $\mathrm{PM}_{2.5}$ and $\mathrm{PM}_{1}$ collected by multi-nozzle cascade impactor in Tokyo metropolitan area, Japan. Earozoru Kenkyu, 22, 126-134 (in Japanese with English abstract).

Okuda, T., Matsuura, S., Yamaguchi, D., Umemura, T., Hanada, E., Orihara, H., Tanaka, S., He, K., Ma, Y., Cheng, Y., Liang, L. (2011) The impact of the pollution control measures for the 2008 Beijing Olympic Games on the chemical composition of aerosols. Atmospheric Environment 45, 2789-2794.

Okuda, T., Nakao, S., Katsuno, M. Tanaka, S. (2007b) Source identification of nickel in TSP and $\mathrm{PM}_{2.5}$ in Tokyo, Japan. Atmospheric Environment 41, 7642- 
7648.

Okuda, T., Takada, H., Kumata, H., Nakajima, F., Hatakeyama, S., Uchida, M., Tanaka, S., He, K., Ma, Y. (2013b) Inorganic chemical characterization of aerosols in four Asian mega-cities. Aerosol and Air Quality Research 13, 436-449.

Pai, S.-C., Yang, C.-C. Riley, J.P. (1990) Effects of acidity and molybdate concentration on the kinetics of the formation of the phosphoantimonylmolybdenum blue complex. Analytica Chimica Acta 229, 115-120.

Paytan, A., McLaughlin, K. (2007) The oceanic phosphorus cycle. Chemical Reviews 107, 563-576.

Suzumura, M. (2008) Persulfate chemical wet oxidation method for the determination of particulate phosphorus in comparison with a high-temperature dry combus- tion method. Limnology and Oceanography: Methods 6, 619-629.

Zhang, W., Zhuang, G., Guo, J., Xu, D., Wang, W., Baumgardner, D., Wu, Z., Yang, W. (2010) Sources of aerosol as determined from elemental composition and size distributions in Beijing. Atmospheric Research 95, $197-$ 209.

Zhu, R., Glindemann, D., Kong, D., Sun, L., Geng, J., Wang, X. (2007) Phosphine in the marine atmosphere along a hemispheric course from China to Antarctica. Atmospheric Environment 41, 1567-1573.

(Received 18 June 2013, revised 9 September 2013, accepted 10 September 2013) 